\title{
ANJOS/ÂNGULOS: DA TAREFA ANGELICAL AO TRADUZIR DA MULHER
}

Barbara Godard York University Toronto, Canadá

"Que é o amor para uma mulher - o mesmo que escrever." Julia Kristeva, Histoires D'amour

"Se conheço o êxtase, estou transposta"

Nicole Brossard, La lettre aérienne

"[O sentido] é um estado constante de fluxo - até que ele possa emergir como língua pura da harmonia de todos os vários modos de intencionar... Se essas línguas continuam a crescer dessa maneira até o fim de seu tempo, é a tradução que ateia fogo na vida eterna das obras e no perpétuo renovar da linguagem. A tradução continua a colocar o crescimento esvaziado das línguas à prova: quão distanciado está o seu significado oculto da revelação, quão próximo ele pode ser trazido pela consciência dessa distância?"

Walter Benjamin, "A tarefa do tradutor"

\section{RESUMO:}

O presente artigo analisa a teoria de tradução desenvolvida no Canadá por Nicole Brossard em Le désert mauve (Mauve Desert) que incorpora as dimensões afetivas e corporais da tradução. Propondo uma teoria feminista do contato cultural como relação amorosa, essa ficção investiga 
o excitamento e os perigos de abraçar o Outro. Nesse processo, reescreve a teoria benjamiana do anjo tradutor com sua noção de uma sobrevida transcendental na intentio de uma "língua pura", para apresentar, em contraposição, uma teoria de ângulos de tradução, tradução enquanto transformação a partir de uma mudança de perspectiva que envolve uma mudança espacial e cultural com uma conseqüente diferença no sentido.

PALAVRAS-CHAVES:

Teoria de traduçãofeminista, Reescrita de Benjamin, Ângulos tradutórios

A criação da beleza envolve inevitavelmente a violência? Essa é uma questão que Nicole Brossard tem perseguido em sua fiç̧ão, ao interrogar o legado da vanguarda modernista e suas figurações de catástrofe violenta nas colisões mecânicas do surrealismo dadá, ou a "beleza convulsiva" dos Autônomos de Quebec ao fragmentar o corpo feminino.' Numa tentativa de transformar os grandes livros modernistas da noite em "lightwood" ' ${ }^{2}$, Brossard engaja-se no projeto que Kathleen Martindale chamou "pós-modernismo lésbico", uma vanguarda cultural caracterizada por uma perturbadora "excessividade" em tornar visível a sexualidade lésbica, abjeta. Em Le Desert Mauve (Mauve Desert), a personagem Mélanie declara: “ un jour je sortirai de la réalité de son scandale. La beauté est avant la réalité... la réalité est un devenir espacé dans la mémoire" (36-7) ${ }^{3}$ e articula a contenda de Brossard com as "ficções do real" que se têm alinhado sob a economia do desejo masculino governada pela pulsão de morte. Brossard dedica-se à questão dos jogos de fim apocalíptico através dos tropos das narrativas entrelaçadas de aniquilação nuclear e assassinato no deserto americano, que formam a matriz narrativa de Le Desert

1. Este ensaia se originou camo "O Trodutor Aprende a Donf̧ar", o terceiro porte de "Frogmentos de um Discursa do Trodutor", presente em "Aux Conadas: Reoding, Writing, Ironsloting Conodion literotures". Université de Montréal, April 17, 1997. 2. Godard 1991, 7-8. A trodusão em le desert mouve é uma tentotivo de fazer o pensomento curvar-se ò "realité du coté de la
lumière" (155).

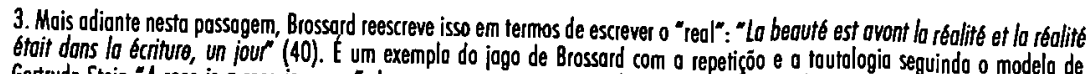
Gertrude Stein "A rose is a roso is a rose". Locan sugere que o uso paradoxal do metonimia pela recussa de ir além do toutrologio no procura do sentido é umo orma poro resistir à mirogem do cogito cortesiono, ele próprio umo tautologia (276).
Mauve por Laure Angestelle e introduz o topos da semiose como descoberta (McGahan). Tal construção de sentido inicia o trabalho de representação do limite no qual, segundo argumenta Lotman, a distinção que uma cultura faz de um "nós" ordenado produz seu tipo particular de um "eles" desordenado, sendo que tais distúrbios levam à criação de uma nova "semiosfera" cultural e produzem valores culturais (142). A excitação e o perigo dessa ruptura são figurados como uma relação erotizada em outro tropo narrativo de Le Desert Mauve: o da tradução. Na história, a tradutora Maude Laures se apaixona pelo texto de Angestelle e investiga os silêncios do texto em busca do significado do assassinato da personagem Angela, a fim de traduzir o livro. Trazendo o ato da tradução para dentro da narrativa e apresentando a tradução como um ato narrativo que produz transformação, Brossard elabora uma teoria da tradução como necessariamente ficção ou poiesis: interpretação que produz sentido de um horizonte diferente de expectativa, ou seja, de um lugar sociocultural diferente - nesse caso, de uma remoção do norte das condições extremas do deserto do Arizona. Desse modo, reescreve-se a teoria de Benjamin da superimposição das línguas como um teste contínuo que revela a intentio de uma "língua pura" em um momento apocalíptico (74-5), a partir de uma perspectiva que insiste nos limites da tradução impostos pelas contingências do desejo e busca explorar o funcionamento e os processos de mediação entre dois corpos (textuais) caracterizados por sua estranha diferença. A tradução como síntese metafórica dá lugar à tradução como repetição anafórica. Nem "naturalizando" nem "estrangeirizando" (Berman) em seus efeitos', a prática tradutória de Brossard se abre a um outro nível de significado através de interrogação e reiteração num processo de lenta sedimentação.

A tradução: uma arte da aproximação, uma arte da sedução - esse é o giro que Brossard dá à translatio. Desde a época do Império Carolíngeo na Idade Média, entretanto, como nota Eric Cheyfitz, a translatio imperii et studii, derivada da retórica de Cícero - que instruía sobre a arte de fala eloqüente e eficaz - , funcionou como uma teoria tanto da linguagem figurada como da tradução. No seu centro há uma cena na qual um orador "civiliza" um "selvagem" através de sua eloqüência, levando humanidade e civilidade para domar terras e pessoas selvagens. A transmissão do conhecimento (studii) tinha como sequiência uma transferência de poder (imperii). Propondo uma teoria da história

4. Segundo Brossard em "la plague toumante": "nos fozemos mois do que fazer componhia uma o outro... Nós existimos em outro

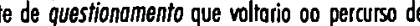
exaustáo cam o qual a resistêncio nos fez fomilior, o fim de nóo ceder ò ordem existente." (LA 44-45 grifos meus) 
como uma substituição cíclica de um império por outro, ela promoveu uma teoria monolítica da tradução de e para línguas hierarquicamente "superiores": o latim ou as línguas da Europa (infracondução e supracondução). A língua do outro é anulada no mito da "língua comum", aquela formada na contradição, contudo, de que o outro que fala o que não se entende e o outro que fala "nossa" língua (intérprete ou informante nativo) são sintomáticos de um problema diferente: o fracasso em reconhecer que a figura do "outro" " fala uma língua e ela é diferente da nossa" (Cheyfitz 109). Duas máquinas metafóricas se encontram, mas apenas uma é entendida como retórica ou arte: a outra é percebida como transparente ou "natural", o que constitui um álibi para a dominação (retórica). Na própria invisibilidade de uma outra língua para o sujeito tradutor, é instituído um modelo de tradução como uma transposição ou metáfora, um transporte e/ou transferência que apaga todos os traços de mediação ou manipulação da linguagem em favor de uma equivalência de sentido na transposição textual. Impulsiona-se, assim, o "aparato perceptivo" do imperialismo e seu sonho que se prolonga, como (im)possibilidade, no devaneio benjaminiano de um movimento acima de todas as línguas na tradução do significado oculto ou cerne; do sentido e não da palavra literal.

A figura da tradução é redefinida na ficção de Brossard para que se examinem suas funções simbólicas e a própria natureza da linguagem como representação, não no movimento em direção a uma "língua pura" e alguma traduzibilidade abstrata como promessa de uma pós-vida, mas nas especificidades tangíveis das línguas, "cette substance mouvante qui, dit-on, entre dans la composition des langues et qui les rend savoureuses ou détestables" (DM 177). Brossard enfatiza as dimensões materiais da tradução tanto através da corporalidade do sujeito tradutor, que se senta ao café para discutir o processo de manipulação lingüística com o autor, como pela plasticidade da linguagem, através da ênfase na repetição com diferença no jogo de sonoridade, numa série "fonossemântica" de significantes que perturbam a "transcendência" (Campos). Centrada na linguagem, a tradução é o ato literário exemplar, chamando atenção auto-reflexivamente para os mecanismos lingüísticos da produção de sentido. Com suas ressonâncias afetivas de tal disjunção de códigos, as diversas sonoridades produzem diferenças mesmo dentro de uma mesma língua, como é o caso da transposição do francês para o francês feita por Maude Laures. Essa transposição envolve uma sutil modulação de fonemas seguindo uma linha de sons, como o jogo do nome "Maude Laures" com o título de sua versão da narrativa: "Mauve l'horizon". Aqui, Brossard inverte o paradoxo da tradução para insistir na diferença no interior da igualdade de uma única língua "nacional", em lugar da ênfase tradicional na igualdade dentro da diferença de duas línguas "nacionais" nas teorias de equivalência.

De que maneira pode a tradução como repetição de uma obra pronta produzir novidade e surpresa? Nesses termos, a tradução se torna mais um meio de figurar o paradoxo da mesma diferença do amor lésbico, com o qual Brossard tem se preocupado desde L'Amer. Seguindo a linha de raciocínio de Luce Irigaray sobre a política de representação dentro de uma economia falocêntrica que privilegia a "homo-sexualidade" (171) — e na qual a mulher é o signo de troca para forjar uma linha masculina de transmissão com o conseqüente apagamento do corpo feminino e das subjetividades multifacetadas -, Brossard ocupa-se da problemática da indiferença à diferença sexual a fim de mostrar como a troca entre mulheres funciona para barrar o simbólico, para romper com o modelo de sentido baseado na apropriação potente do outro pelo mesmo ou aufheben. "Como fazer sentido coletivamente" sendo mulheres é um problema abordado por Brossard em La Lettre Aérienne. "Como assegurar as trocas entre nós mesmas, como articular nossos pensamentos, nossos corpos, nossas emoções - nossa subjetividade, enfim - de modo que possamos configurá-los objetivamente?" (LA 112) A erotização das relações entre tradutora e autora é a economia alterada de troca, que Brossard enfatiza em Le Désert Mauve, por meio do encontro do eu e do outro numa outridade do eu como exotopia e êxtase. Tradução é antes uma cena de sedução ou convers(aç)ão do que uma conversão em um movimento de dominação. Nela, Brossard explora outra dimensão da figura da translatio como "tentação" pelo poder retórico de "desenvolver" (elicere) ou civilizar - elicio, evocando o "subterfúgio da sedução" - no modelo de eloquêencia de Cícero (Cheyfitz 114). De que modo o leitor/tradutor é arrebatado pelo êxtase? E se, pergunta Brossard, o poder da sedução fosse tornado visível? Reconhecer a força do desejo daria lugar para $o$ outro (linguagem)? Levantadas por Le Desert Mauve, essas são questões que avançam até o espaço entre as línguas, para expor a violência fundadora da retórica e os limites irredutíveis do conhecimento do outro, para tornar visível o potencial de traição nesse intervalo. $O$ entrelugar se torna um local de interanimação, de trabalho de nexo-anexação entre um campo de forças de aproximações e acentos. $O$ magnetismo do desejo alinha significantes em uma certa combinação e inclinação.

Ocupando uma posição central em Le Desert Mauve, entre a narrativa de Laure Angestelle e a versão dessa narrativa por Maude Laures, está "Un 
zar uapue o seu trabalho de discernir narrativa da traduitora que estân prestes a escrever. Como o interstício, que tanto figura a possibilidade de disputa entre proximidades ou antipatias quanto funciona como ocasião e lugar de união e/ou contestação, o entrelugar se torna o lugar da mediação, do trabalho. A tradução, como escreve Bakhtin, é um trabalho de "reacentualização"; não é uma tarefa dada, mas uma que deve ser desempenhada ou atualizada, através de um esforço de entendimento, numa "recepção ativa" ou reconhecimento. $O$ sentido não é algo que o falante/autor "possui", mas uma forma de "citação" ou empréstimo de outro, recontextualizado com efeitos cinéticos. Tal "repalavramento" (Bakhtin DI 337) constitui sentido como evento na interação axiológica entre dois sistemas de valores (Volosinov 117). O entrelugar não é um signo da elisão e violação numa insistência da lei, mas é o silêncio que se torna visível na letra, ao qual é dado um título, o qual é legitimado por uma assinatura e é dado como prova de complexidade e resistência. Aqui, o discurso da transparência e da "facilidade de conversão" é deslocado por um discurso da opacidade e da auto-reflexividade no processo do encontro com a diferença. $O$ difícil trabalho da tradutora se toma visível - o trabalho de virar discursos ao avesso, de alterar sua enunciação e sua mensagem, de expor as extratificações, as relações de poder e de saber e a perspectiva interessada de onde elas são construídas. Essa não é uma relação de analogia da ordem do mesmo - a qual presume uma economia de equivalência (e reciprocidade), tornando possível que uma identificação substitutiva constitua objeto singular - , mas uma de contigüidade, operando lateralmente através das combinações ao longo do eixo horizontal no qual as diferenças deslizam umas sobre as outras numa cadeia prolífera. Palavra se liga a palavra, imagem a imagem, elemento a elemento, voz a voz, através de acumulação que produz um sujeito agregador, que ramifica em vez de convergir. Forjam-se mais ligações entre leitora, tradutora e escritora para produzir socialidade e solidariedade através de uma abertura recíproca à outra. Entretanto a outra guarda seu mistério, pois, nessa saída em direção ao outro, mais transformações são produzidas no sujeito tradutor que no texto traduzido. Novos horizontes se abrem para ela quando ela escreve na página final: "elle (a personagem/'ela') parle et réveille en moi l'horizon" (220). Em contraste com a finitude e o encerramento no trabalho analógico da substituição da metáfora,

5. Bermon uso o termo "repaloviomento" (IT), enquonio Letevere emprego "reescrito". as relações no eixo metonímico de combinação são caracterizadas por processo e abertura. $\mathrm{O}$ movimento infinito da metonímia é aquele do desejo contínuo e da conclusão irrealizável ${ }^{b}$. Cada significante submete-se a outro e depois a outro, num interminável jogo de diferença e revisão que estabelece o palimpsesto ou "dialogismo" (Bakhtin) como signo de re-inscrição e transformação.

A sedução está presente como uma ficção ou modelo do processo de tradução em Le Desert Mauve, onde uma mulher, desperta por uma carta de amor encontrada em um livro escrito por outra mulher e movida pelo desejo (transposta, enfim), começa um corps à corps com o livro e apresenta uma versão a partir do seu próprio ponto de vista ou ângulo de percepção: "Sua palavra contra a minha" (155). A autora não é o único sujeito: seu livro é uma carta lançada como um convite, minimizando espaços até a outra distante, que, ao responder, recompõe a carta de dentro das contingências de sua posição como sujeito da enunciação. Espaço e tempo, segundo Bakhtin, são percebidos como uma função do ângulo de percepção e produzem um "cronotopo" diferente (DI 84). A preocupação de Brossard em efetivar a "alteração de sentido" está esboçada em La Lettre Aérienne: "Sendo um problema de pele ou de lingüística, parece-me que qualquer alteração de sentido ocasiona uma ruptura da realidade, senão apenas no modo como percebemos essa realidade. "(81). Essa hipótese depende de um argumento anterior de que todos os textos, sejam de ficção, teoria, ou o sistema patriarcal, são construções relatadas a partir da perspectiva interessada de alguém. Eles podem ser reescritos, modificados, revelando, assim, coisas novas e outras. Para Maude Laures, a alteração do lugar de percepção e articulação produz um sentido diferente, pois a tradutora torna o texto "seu", substituindo a "frieza" da outra pela "excessiva sensibilidade" de Mélanie/Laure (155). Maude examina as declarações da personagem Kathy Kerouac quando esta diz que "les hommes ont inventé la mort parce qu'ils y pensent" (129) e quando, com sua amante Lorna Myher, ela dá a palavra ao essencial, e favorece as exigências da invenção: "Je fais ma vie. J'invente ma réalitê" (133). Nas "notes de lecture" ou no relato de sua leitura (ativa), a tradutora surpreende-se por passar dois anos absorvida pelo livro de uma mulher sobre a qual ela nada

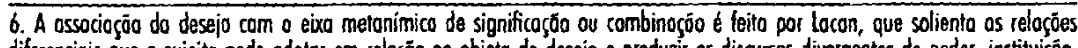

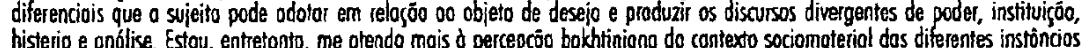

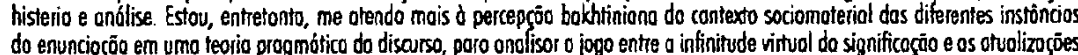

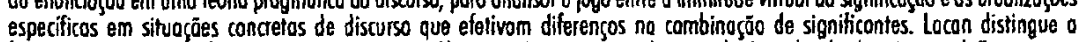

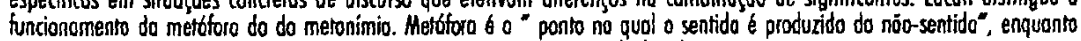
metonínia empregyo o "poder de subverter os absticulos do censuro sociol" (266). 
sabe, e progressivamente cede ao seu crescente desejo de "transformação" (59). "Eros", como sugere Brossard, "está a serviço em toda escrita" (LA 83). Seduzida por sua leitura ( $D M 60)$, Maude se envolve apaixonada, física e especulativamente com o texto, e se inscreve como um sujeito virtual na tradução. A transformação de Maude é legitimada por sua assinatura, que aparece na nova página de título de "Mauve l'horizon", impressa no início da parte final do livro. Não apenas uma voz em palimpsesto dentro do eu enunciador da enunciação dupla do tradutor' ${ }^{\prime}$, Maude Laures transforma-se em personagem, "ela", em sua própria ficção, ao inventar sua realidade e incluir um auto-retrato seu como tradutora, na parte dos estudos sobre as "personagens" na narrativa. Objetivamente, através da ficção, é acionado aqui o processo da troca de subjetividades, que Brossard explora em La Lettre Aérienne: "Se o 'eu' permite toda ramificação... se o 'eu' é fictício..." (44). Um duplo movimento se dá: Eros deixa-se levar à medida que "a mulher faz seu sonho", enquanto "o conhecimento a traz de volta à ficção" para inventar um certo futuro (LA 79). A ficção da tradutora detalha sua abordagem de Le Desert Mauve, sua preparação para o ato da tradução e o trabalho de transformação, enquanto ela considera em turnos os diferentes elementos de uma narrativa - lugares e objetos personagens, cenas, dimensões -, dividindo o texto em fragmentos formais para depois recombiná-los, em sua própria versão, como discurso indireto. $\mathrm{O}$ texto concretiza o convite da tradutora/professora aos seus alunos para se exporem aos acidentes da sorte, a fim de serem estimulados pela surpresa: "Aimez les livres... car vous ne savez par quel hasard, au tournant d'une phrase votre vie s'en trouvera changée" (122). Isso concebe a leitura como a "plataforma de mudança" de La Lettre Aérienne, a qual postula mudanças tão radicais nas ficções do real quanto a vertigem da espiral inexoravelmente reveladora.

Tal arrebatamento gera, na narrativa, um movimento que vai do distanciamento para a cumplicidade com personagens e eventos à medida que a tradutora os reacentualiza e os escreve dentro de sua própria ficção, transformando morte em vida. O corpo de Angela Parkins - que no texto de Angestelle é apenas um traço esboçado no chão, um corpo sob rasura —, quando acometido pelo desejo de Mauve em conhecê-lo em um movimento especulativo, vem à vida como o "cadavre exquis" nesse texto coletivo que antecipa a formação de uma comunidade que faça sentido coletivamente. ${ }^{8}$ Maude utilizase da narrativa de Angestelle como base para re/construir as circunstâncias em torno da morte de Angela e, ao trocar "deserto" por "horizonte", entra em diálogo com a autora do texto a ser traduzido. Maude examina o "besoin d'aube, désir de défier la nuit" de Mélanie em tensão com a "volonté d'en finir" (150) de Angestelle. "L'aube," como inicia essa parte, "est ce qui commence, distorsion de la nuit étrange, coloration du sentiment, une version consignée de la lumiére" (150). O livro de Angestelle assemelha-se a uma "pierre tombale" (55) escura e silenciosa - um trocadilho com seu nome que pode ser traduzido como Angelstone - na qual Maude procura um vislumbre de luz. A manhã em que ela inicia seu projeto de "apreender o sentido de uma estranha estória" num contínuo "acte ininterrompu de l'interpretation" é iluminada por um "céu azul" (58) sobre a neve de dezembro (57). Na versão de Maude para o texto, "Mauve, l'horizon", que constitui a parte final do livro de Brossard, Angela fala da existência: "Elle dit que tout va recommencer, paroles, sentiers, sentiments..." (219). E, através da repetição, tudo realmente começa outra e outra vez. Inícios criativos, em vez de completo conhecimento das origens, é o que Brossard antecipa nessa teoria da tradução onde a prioridade do texto "fonte" é meramente temporal - um impulso à criação -, e não de fundação. Relações seculares e de seqüencialidade entre línguas, e não sagradas ou de hierarquia. "A beleza", como ela diz, está "avant la realité... angle de reflexion, neurone sélectif, langue à la source" (160). A questão da seleção da língua está relacionada àquela da mudança de perspectiva numa proposição de curvar a realidade em direção à luz (155).

Brossard joga com a ambigüidade do processo de tradução que é, simultaneamente, abraço e agonia, excitação e violência. "Corps à corps", como ela descreve a relação de Maude com o corpus textual, literalmente quer dizer combate corpo a corpo. É o sentido textual da frase que o programa narrativo atualiza na ficção da tradutora, enquanto o sentido figurado determina o texto "fonte" de Angestelle, que termina no assassinato de Angela. A ficção de Brossard pergunta-se explicitamente se a hermenêutica da narrativa produz uma rasura violenta através da incorporação do objeto pelo sujeito ou um encontro amoroso em que o sujeito e o objeto coexistem lado a lado, mutuamente constitutivos. Diferença e distinção são tomadas, aqui, não como separação e

8. Os surrealistas desenvalveram o "codarre exquis" ou codb́ver extroardinario. Composto coletivemente, essa nourotiva é dirigido

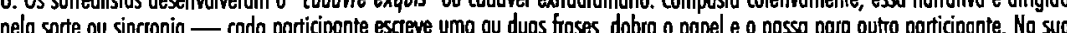
"pela sorte ou sincronia - coda participonte escreve uma au duos froses, dobro o papto 
incorporação, mas como conexão. Morte ou amor? Qual é o fim apropriado para a ficção? Ou para a tradução? Que força tem a palavra para lançar a ponte através da incerteza? Qual tipo de ponte? Estrutura fixa ou reversível? No que Brossard chama de "transmissão fervente"(Nuit 13), a união entre mente e corpo, entre corpo e corpo, signo e signo, é efetivada através da imagem que causa linhas de desejo, engendrando relações de movimento - e mudança - efetivas e afetivas. Fragmentos e citações que se tornaram fixos ou mortos são reescritos em um novo contexto - deslocamento através da repetição como uma estratégia de modulação, afetando o significante para fazê-lo vibrar e ressoar em outra teia ou rede de significação, com intensidade diferente, com energia diferente.

Nas páginas finais da ficção, a tradutora dança com duas das personagens mulheres, enquanto eu/Mélanie dança com Angela. Sua passagem pelo livro produziu uma mudança de ritmo que trouxe, ao mesmo tempo, essas três mulheres até a pista de dança; elas se movem ao sabor da música, sincronizando seus movimentos numa forma comunal. A tradução é uma mudança de ritmo, como sugere Maude em seu auto-retrato ficcional: "Tu change le rythme" (121). Tal jogo de leitura/reescrita (121) produz uma reorganização ou um "retrabalhar" do texto sob restrições diferentes. "Uma questão de tratamento" (155), esse é o modo de "tornar visível e participativa a passagem para a sua língua, para acelerar os sentimentos, com os efeitos de cores resplandecentes, o deslizamento" (63). Excitante como possa parecer, esse "deslizamento" demonstra a quase impossibilidade de coincidência e equação de sentido entre articulações, além da força da incomensurabilidade na tradução entre as instâncias da repetição e suas contingências de temporalidade e lugar. Brossard expõe a maneira como a epistemologia funciona através das modalidades de estrutura infletidas pelo desejo. A diferença é irredutível mesmo quando essa determinação, como finitude fundamental, se abre para a positividade de toda limitação concreta em uma mudança funcional nos sistemas do signo (ou na semiose do jogo do limite). A leitura de tradução de Brossard é antes epistemológica que retórica, é sobre força e posição na constituição do sentido. A escrita é sempre enquadrada por um ângulo de visão situado e pode ser reenquadrada se ressituada/recitada em outro contexto. Ela está, além disso, aberta à ação da carga restritiva do enquadramento. No trabalho de reformulação ou reacentualização, a transmissão de significantes encena uma travessia de limites e uma quebra de leis. Dentro de uma multiplicidade de enquadramentos ou ângulos, existem muitas combinações ou encontros possíveis, uma proliferação ou expansão de potenciais criativos. Nessa ficção sobre o trabalho de uma tradutora, Brossard observa quantos encontros são orquestrados e utilizados. Ela coloca as identidades (textuais, pessoais e lingüísticas) em questão - intensidades de desdobramentos rítmicos, especialmente. Estratificadas, quando se fala de palavras habitadas pelo outro, as identificações são parciais, dispersas. Dentro de um entrelaçamento de textos, as questões de autenticidade, de identidade, são abordadas lateralmente através do ângulo oblíquo do outro, e então deslocadas pela pergunta: em relação a quê? A "exotopia", sugere Bakhtin, abre-se às diferenças entre autopercepção e percepção do outro, entre "eu" e "ela" ou "eu"[ I ] e "olho"[eye], um excesso de visão da posição do outro para compensar a inevitável falta de visão da "minha" localização específica. A possibilidade de resposta às particularidades da perspectiva do outro introduz uma dimensão ética na relação do eu e do outro, no discurso de dupla voz da tradução. $O$ outro termina por estar inesperadamente no centro da (auto) reflexão de alguém. Nessa confusão de sujeito e objeto, de "eu"/"ela", na mistura de línguas, a lógica do primeiro e do segundo, a lógica platônica da origem e da representação, do Um e dos muitos - a lógica da identidade - é derrubada: a língua-mãe não pode reivindicar nenhuma prioridade como o discurso da verdade. Relações são estabelecidas não a partir de um ponto original fixo que irradia exteriormente, mas entre os processos através dos quais a diversidade se constitui de várias interações mútuas. Dentro e fora não são termos absolutos, mas são situados reciprocamente em relação ao momento da fala dentro de restrições institucionais específicas. ${ }^{9}$ A tradução é a enunciação de um sujeito cujo processo de transposição é passível de investigação. Quais são os riscos do tradutor? Para que fim é efetivada a manipulação textual? Está implicado aqui o movimento da translatio para a interpretatio, de uma transposição naturalizada para uma especulação desenfreada das potencialidades de transformação. As potencialidades ficcionais de imaginar a diferença através de uma afirmação "como se", ou uma interpretação hipotética, rompe com o movimento da lei no encerramento do mesmo.

A mudança do ângulo de visão do tradutor que reescreve produz uma diferença desfocada da versão do autor, iluminada pela variação do clima de inverno do Norte, por diferenças de segmentação e ênfase, de insistência e ritmo. Brossard demonstra isso na parte central do livro, "Un livre à traduire"

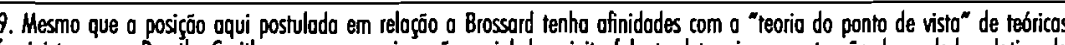
reministas como Dorathy Smith, para quem a insergáa social do sujeito folante determino a pretensáa de verdade relativa da orticuloçäo, ev, aqui, me prendo mois oo entendimento dinâmico das poliricos de discurso desenvolvidas por Bakhtin na sua teoría

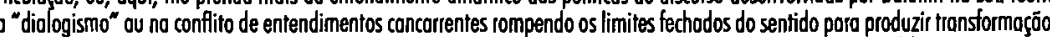

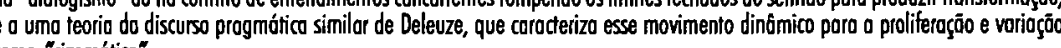
como "rizomótico". 
(Um livro para traduzir/Um livro a ser traduzido), onde a tradutora isola e reenquadra as dimensões, objetos, cenário e personagens, em seu esforço para chegar a entendê-los. Em lugar de incorporá-los numa narrativa inconsútil, esse processo investigativo destaca-os como entidades discretas, vira-os por todos os ângulos, no lugar da mediação ou transferência entre tradutor e autor. Os apoios narrativos de organizar o conhecimento para interesses específicos são postos em conflito com o sentido como flash ou insight, ou como verdade revelada. Em vez de focalizar o sentido no texto-fonte, do qual outras versões são uma derivação infeliz ou uma distorção, ou no texto-alvo e em um leitor implícito em outro sentido singular, a narrativa da tradutora focaliza o processo de negociação e a força de uma nova reelaboração, dentro de restrições sociais e históricas que estruturam sua retórica. A tradução é uma transcodificação, onde o deslizamento de significantes, em sua combinatória, produz um efeito de transformação.

Deslizamento, "dérive" ou deriva - estes são substantivos constantes na obra de Nicole Brossard em relação ao "delírio criativo" (Nuit 22), que é o movimento do desejo transmitindo uma imagem a outra, na constituição da rede de sentido. Essa breve referência à semerótica da tradução conduz ao processo utilizado por Maude Laures, a (tr)a(d)utora na ficção de Brossard, cujo metacomentário sobre a atividade de relacionar um corpo textual a outro, uma língua a outra, desperta o desejo da tradutora pelo encontro ou conexão. Seu engajamento com o processo de manipulação é emoldurado como resposta ao discurso de outra mulher. Esse é o desejó do sentido, na acepção de "êxtase" ou "gozo" textual presentes na figuração de Roland Barthes: o discurso amoroso como deslizamento das bordas cortantes de fragmentos ou discursos textuais uns contra os outros. O gozo, segundo ele, altera suposições através da diferença que está "além e junto ao conflito"(15). Um texto impossível e indisciplinado como esse está "fora da crítica": "não se pode falar 'sobre' um texto assim, só se' pode falar 'em' ele, à sua maneira, só se pode entrar num plágio desvairado" (22). Dessa maneira, o comentário de Maude Laures manifesta-se não como uma análise textual fora da narrativa de Angestelle, mas a escreve dentro do centro do texto para repeti-la na tradução.

Tradução como somograma ou "rythmographe" (McMurray 26) essa é uma maneira pela qual Brossard figura o processo de inventar uma língua, que é o trabalho da tradução, o projeto de produzir sentido entre textos através de uma investigação especulativa das operações da produção de sentido e suas dimensões afetivas. Pode-se formular isto como a diferença que "L" (elle/ela) faz, a diferença feita pela outra mulher na política de articulação e discurso. A tradutora torna-se escritora, celebrando a maneira com que ela "manimulherpulou" [womanhandled] o texto (Godard), pela colaboração com a autora e sendo sua parceira em intrincados passos de dança. Na prática, isso resulta em tradução 'imprópria' ou transposição criativa, também conhecida como tradução homolingüística ou "intralingual" (Jakobson). Tal "repalavramento" é figurado no significado lexical de tradução como interpretação ou explanação: "para expor o significado de (conduta, gestos, etc.); para expressar uma coisa em termos de outra dentro da mesma língua" (Oxford English Dictionary). "Homo", o "mesmo" que é simultaneamente diferente (a outra mulher) - o jogo de palavras é crucial, "desabrigando" ou tornando visível o trabalho da transposição. $O$ paradoxo da mesma diferença, do desejo entre mulheres. Opondo-se à tradução como dominação, tal prática respeita a autonomia e a diferença de outra cultura, de tal modo que ela é incapaz de produzir uma tradução que possa ser uma apropriação, ou reluta em fazê-lo. Indo e vindo entre múltiplas perspectivas de 'eu' e 'outro', a tradutora re-forma subjetividade e textualidade numa montagem de identidade, uma conexão interrelacional, e reformula a tradução como tropo - um atravessar persistente entre pontos de observação e intenções, entre representação e performance em um texto-sob-(auto)-re/visão. A tradução como um processo, mais do que como um produto, é enfatizada nas 130 páginas distribuídas em "Un Livre à Traduire", em contraste com as 40 páginas de texto para "Le Desert Mauve" e um número similar para sua reescrita.

Que diferenças de inflexão existem entre a versão de Laure e a de Maude? Que diferença faz uma palavra? A ficção interroga esses lances no movimento da transposição. Não milagres ou maravilhas, certamente, mas questões de vida e morte, segundo a versão da tradutora, na qual "[Angela] dit qu'en realité il suffit de quelques mots concis pour changer le cours de la mort"(220). Na reescrita de todo o trecho, Maude repete certas palavras-chave em combinações diferentes e transforma a ênfase na incerteza e em palavras como "morte" para a ênfase na "fé" e em palavras como "defesa contra a morte"..$^{10}$ Tornando possível a dança, a repetição de gestos pelo tradutor, a

10. Na versáo de Loure, os palavros são usodos diferentemente - um certo número de polovvas-chove se repete, mas em um novo conterto: "elle dit quif ne rout pos renoncer, que rien n'est impossible sil to mémoire occomplit dans l'improboble la certitude qu' en soi veille à Tharizon à la beaute, elle parla de l'altachement que nous avons pour certoins mots el que ceux-ci sant comme des

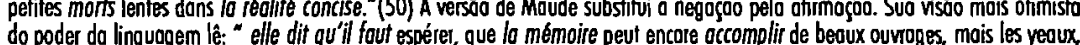

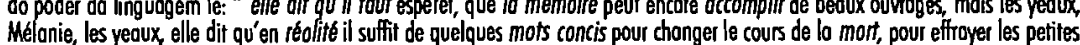
douleurs, elle parle et réveille en moi l'horizon" (220). As poloviros sublinhadas sốo repetidas e recontextuolizados pora ofereecer un ôngula diferente da questióo.

REVISTA DE ESTUDOS DE LITERATURA
Belo Horizonte, $v, 5$, p. $155-182$, out. 97

[1] 8 7) 
tradução de Maude Laures não pretende suplantar a autora. Pelo contrário, é o desejo de encontrar a autora - de trazê-la à vida para descobrir mais sobre as personagens e sua representação - que anima a atividade da tradução. Laure Angestelle é o primeiro portrait na galeria de estudos de "personagem" feita por Maude em "Un Livre à Traduire", onde ela se pergunta se a ficção é "autobiographique" ou "fantaisie" (89-90). O auto-retrato de Maude denota seu desejo de entender a razão de fragmentos tão curtos, numerados como capítulos, "qui donne à l'homme long un caractère fictif" (120). Por que essa parte foi separada e rotulada como "fiç̧ão"? O que isso implica na exigência de verdade do paradigma nuclear que a história propõe como "real"? Na terceira parte sobre Kathy Kerouac, entretanto, Maude examina as ligações forjadas pela linguagem entre Kathy e sua amante, Lorna Myher. Atenta ao movimento das "vozes ativas e passivas", Kathy passa horas absorvida em sua contemplação, notando "seus pontos de encontro e ruptura, tentando entender o que, dentro do ritmo, poderia produzir tamanho grau de tensão, alternância de desejo e emoção" (96). Na alteração de vozes e perspectivas efetuada pela tradução, os cortes e conexões feitas entre objetos, entre signos, são modulados por diferentes ritmos. E nem a tradutora soluciona claramente, em sua versão, o mistério do assassinato de Angela Parker, cujo motivo o "Le Desert Mauve" de Angestelle não revelou. A diferença é uma inflexão, na qual Maude se inscreve como "eu", virtualidade dentro da perspectiva narratorial de primeira pessoa, $e$ responde passionalmente ao abraço da personagem Angela, cujo rosto se aproxima do dela nas páginas finais do livro (219). Pois a fiç̧ão de Laure Angestelle produziu em Maude Laures desejo pela personagem, Angela, desejo que impele Maude, dentro das páginas do livro, a repetir a relação do escritor com seu "personagem" trazendo-a à vida pelas palavras e interferindo na mudança das palavras para que ela não morra. Suas diferenças se conectam através de uma transmissão de som, repetido e reformulado no momento em que "Angestelle" (Algelstone/ ela-anjo) é modulada em "Angela" (ela-anjo a partir de uma perspectiva diferente) para trazer "Laure" ao lado de "Laures" (Laure pluralizada). O deserto então se tinge de malva ("mauve") quando colorido pela paleta de alvorada de "Maude". Esse tipo de conexão pelo do som das palavras e não pelo enredo constitui uma verdadeira "baroque d'aube", como Brossard entitularia seu romance seguinte. Na versão de Maude, "l'homme long" é reescrito como "l'hom'oblong" - homem louro [homo blonde] —, sublinhando a alteração em sua versão para privilegiar as relações entre o mesmo, sem a intrusão violenta de um terceiro diferenciador. Esse jogo de homônimos em uma série fono-semântica de variações ou transvocalizações consiste numa das principais práticas de tradução de Brossard. Ela desloca a lógica da sintaxe para transmitir conexões surpreendentes entre diferenças, implicando uma sobreposição entre as intranarrativas.

Traduzir no plano da sílaba ou palavra preservando o som, e não no plano da sentença ou proposição, vertendo o sentido do original, é a prática de escritores experimentais como Louis Zukofsky e de humoristas como Luis Van Rooten em seu Mots d'Heures: Gousses Rames. Brossard insere, em Le Desert Mauve, sua ficção sobre tradução, a experiência de vários anos de ativa tradução, tanto ao ser traduzida (cinco de seus livros surgiram em inglês entre 1980 e 1986), quanto ao traduzir. L'Aviva (1985), pertencente à tradição de experimentação poética, é apresentado como tradução cara a cara do francês para o francês. Desenvolvendo repetições recombinatórias que haviam sido características de Picture Theory - ficção anterior de Brossard —, L'Aviva pode ser considerado um "lipograma"ll, ou uma estrutura marcada por extremo apuro formal, à maneira da sextina. Embora sejam poemas de seis versos, eles diferem da sextina porque a repetição de palavras em $L^{\prime} A v i v a$ ocorre não somente ao final dos versos em toda a série de poemas, mas também entre o poema e sua tradução (l'en suite traduite), e faz uso freqüente de homônimos ou "identicals", comuns aos sonetos de Mallarmé, em lugar de repetições invariáveis. A ênfase, nesses poemas, está na variação sutil de possíveis sentidos dentro de um grupo restrito de palavras em língua francesa. Apesar de introduzida como "tradução", a repetição envolve um "repalavramento" em francês, assim como ocorre em $L e$ Desert Mauve. Realmente, os ecos temáticos entre poesia e prosa são surpreendentes, em especial nos dois últimos poemas, que abordam a emoção, a escrita, a tradução e o êxtase orgásmico. Os dois versos finais marcam um deslizamento do despertar através dos sons para um arrebatamento do ser: "toute d'éveil d'être en ses cheveux ouie" (22) é modulado em "d'être en ses cheveux j/ouie" (23)."

Enquanto Le Desert Mauve expande esse exercício da repetição para a estrutura dos fragmentos de cinco páginas em cada uma das duas versões da narrativa, o romance também apresenta, tematica e formalmente, a tradução recíproca entre francês e inglês de Brossard e Daphne Marlatt. Publicada em dois volumes, essa colaboração entre escritoras inicia-se com o poema Mauve, de Brossard, traduzido para o inglês. Significativamente, à luz da ação narrativa de Le Desert Mauve,

11. Lipogromo é o termo usado paro experimentos de escrito sob um conjunto de restriç̧ess formais, feitos pelo grupo francês oulipo (Ouvoir de litterature potentiale)

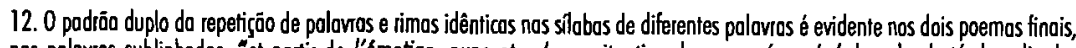

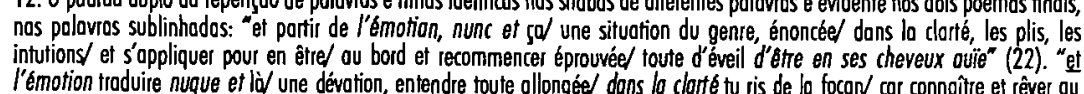

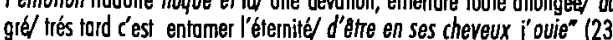


Será o $s$ em Maude Laures uma marca do plural feminino ilimitado,

Marlatt acrescentou um poema à sua "transformance", publicada com o mesmo título. O poema de Brossard, que se revolve em torno de palavras-chave da autora, como "réalite", "virtuelle", "émotion", "peau", "fiction", e conclui com os versos "fiction culture cortex $M A U V E$ " (10), é traduzido por Marlatt precisamente com as mesmas palavras (18). Uma vez que o que os precede na página está escrito em inglês, eles terão som diferente se lidos em voz alta. Marlatt continua, além do final da série, inventando uma nova estrofe que repete esses dois versos em ordem diferente, repete o último verso em ordem inversa, e continua o jogo com o som "mauve" em inglês, dando a ele uma nova cor, uma "mancha" ou "analogia". ${ }^{13}$

Apropriando-se das palavras de Brossard e (re)montando-as em seu próprio poema, Marlatt emprega as estratégias de tradução de Maude Laures e dança em ciranda [rings round] no texto de Brossard. Em sua metamorfose de tradutora em autora, na tradução do poema, Marlatt transforma uma insistência na repetição fiel em transposição poética, pelo processo de repetição com diferença. $O$ último poema da série de traduções, como um refrão, é também uma resposta na forma de variação de um tema característico da renga, de colaboração poética. Realmente, o segundo volume, no qual o poema "Character", de Marlatt, é traduzido por Brossard como "Jeu de lettres", convida à comparação com a renga. Marlatt trabalha tópicos centrais para Brossard como gênero, ficção e identidade, considerando especificamente a força da linguagem em autenticar, dominar, através da assinatura que confere identidade e "caráter". Ter "nenhum caráter" é ter nenhum limite. Mulheres que não têm caráter são excessivas:

s/he:

s plural in excess of he
13.
MAUVE

cortex fiction culture

stoins the other

mew moiwo mauve

molvo rose core text

fiction rings round

skin immersed in

resemblance takes

the stain, sense
roseblue in tissue re-

roseblue in tiss assim como do excesso da tradutora? Deve Le Desert Mauve, com suas meditações sobre o excesso, ser lido como essa troca entre poetas? Se há ecos do sublime da tradução em excesso, a ênfase no diálogo poético traz os anjos de Benjamin de volta à Terra. $O$ título de Brossard recontextualiza a preocupação de Marlatt em "go[ing] beyond herself" (ir além de si mesma) para focalizar o espetáculo da linguagem. No seu "jeu de lettres", o jogo de letras de Marlatt com o " $s$ " serpenteando no espaço da página, "biting through the traces left/ across her body writing/ you" (mordendo os traços restantes/ através de seu corpo escrevendo/ você) é reescrito como o "l" de "l'excès du désir de l'élan". Brossard conclui esse poema com um jogo de palavras no " $l$ ", que se detém mais na permutação de sílabas e na plasticidade da linguagem e menos nas ligações temáticas, apresentando o paradoxo da estaca como arma e defesa no texto de Marlatt, onde o "s" é partilhado pelo "signor, sister, son, sire, soprano" (senhor, sóror, descendente, ancestral, soprano). Ao reescrever a página final, Brossard torna o poema "seu", introduzindo alguns de seus temas característicos, como "vertige" e "corps":

\section{sibylle si belle elfe ellipse, la lyre}

elle a de plus tout intérêt à

couper court au vertige des vestiges

en travers de son corps écrivant

toi

Se, como sugeri, tais práticas de transvocalização e repetição com variação podem também ser encontradas em Le Desert Mauve, suas estratégias e princípios de tradução são aquelas da paráfrase e de mudança na pontuação, a fim de alterar a ênfase entre as versões e tomar evidente a atração entre duas mulheres. Nesse jogo de repetição com variação, o romance vai além dos experimentos de Brossard com tradução poética em número e diversidade de variaçōes. Seu efeito cumulativo é mudar a tonalidade emocional ou "voz" na qual os eventos são narrados. Isso se toma mais evidente na parte final em que Mélanie e Angela se encontram num bar, pouco antes desta ser assassinada. A empatia de Maude pelos personagens que se apaixonam contrasta com o julgamento mais distante de Laure e sua insistência na força do "real". Enquanto, na versão de Laure, o ambiente do bar é estridente, na versão de Maude os mesmos sons e gestos são harmonizados pelo impulso de paixão que leva Mélanie até Angela. Marcando este contraste, a versão de Laure oscila entre

\section{REVISTA DE ESTUDOS DE LITERATURA}

Belo Horizonte, v. 5, p. $155-182$, out. 97 
"Rien n'est sensuel" e "tout est sensuel" (49), enquanto a de Maude declara apenas que "Tout est sensuel" (219). É essa substituição da negação pela afirmação do poder criativo da linguagem na invenção do utópico amor lésbico que caracteriza a perspectiva de Maude Laures. ${ }^{14}$ Enquanto Angela está "perdida", na versão de Laure, ela se adianta para tomar Mélanie nos braços, na versão de Maude. Pois, na articulação de conceitos entre versões, não é só o que é transformado que faz a diferença, mas também o que é incluído ou excluído. Assim como a inclusão do abraço lésbico muda o colorido emocional do texto, também a estrutura política é transformada na versão de Maude Laures quando as frases em inglês, incluídas no meio de uma frase em francês no texto-fonte, são ou excluídas ou traduzidas para o francês - como, por exemplo, quando a frase "Of course Mélanie is night teen" (50) é traduzida por "Mélanie, fille de la nuit" (220). Na verdade, a reordenação de toda essa parte é significativa ao mudar o protocolo de endereçamento para que a narradora (escritora e/ou tradutora) fale diretamente com Mélanie: "Mélanie, fille de la nuit, que s'est-il donc passé?" (220), ao passo que, na versão de Laure, esse endereçamento é feito com uma pergunta geral ou retórica: "Que s'est-il passé?" (50). Maude, aqui, funde-se com os personagens na ficção, entra através do espelho para dentro do mundo representado de Laure Angestelle, uma fusão de sujeito e objeto. O efeito é mantido mesmo depois da morte de Angela, quando, na versão de Maude, demonstrando o poder da memória que se mantém viva nas palavras ${ }^{15}$, a imagem do sangue é transmudada em aurora rosada.

Uma tradução assim, "imprópria", evoca não somente impropriedade sexual, mas também a contaminação da colaboração ou conversação. Contra o

14. Os dois relatos do panta de visto de Angela no nota 10 demonstrom essa substituicão de uma perspectiva negoliva por umo positiva, que é tombém evidente no passagem precedente da mesma ponte. "Je demande une autre bière. Quelq'un me fouche I'epoule. Angelo Perkins est la, alerte, vive, crve et je suis si lente d comprendre combien so présence m'exalte. Elle dit une bonalité puis circule dons les tobles. Lo musique est trop forte. Les trois femmes ont trouvé des partenaires. L'homme de la piscine est mointenont assis a une table ovec deux hommes. Lo musique est trop forte. Rien n'est sensuel. Les corps s'ollongent et tont des ombres comme des cheveux dans le visoge des filles, disposent de leur sounire bosant. Tout est sensuel. Angela Porkin regarde dans mo direction, dessine dans 1 'air un mouvement circulaire ovec so main, oui comme si elle me faisait signe, puis ello pointe du doigt en direction de la piste de donse. Lo musique est trop forte. Lo mussique est trop douce. Le carps d'Angelo Porkins est fonotique, rempli d'urgences. II bondif comme un onimol fougueux, coppricieux, voltige et plane éperduement, éperdue Angelo

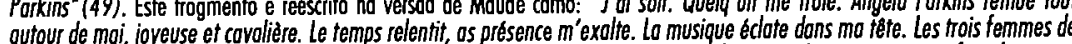
lo piscine ont trouvé des partenaires. L'thomme maigre converse ovec deux outres hommes. La musique tape fart. Les corps

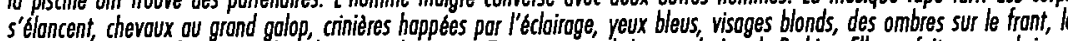
sourire emporte des filles. to couleur des pestes bosanées. Tout est sensuel. Je regorde Angele Parkins. Elle me fait un grond signe, vient vers moi, me prend por lo taille. lo musique est trop forte. Lo musique est encore trop douce. Le corps d'Angelo Porkins cobriole, chevreuil fou oux yeux pleins de lubies. Corps de voltige, corps de vertige... Puis so joue enfin ropproché (219)

15. A primeiro linho do porágrofo final na verš̄o de Loure é: "Puis ce fut le mauve de l'aube, le desert et la route comme un profilsanglant" (51). No versóo de Maude, lê-se: "Puis ce fut le profil menoçant de tout chose. Puis l'oube, le desert et mouve, profilisonglon" perigo da associação com a negatividade na metáfora da tradução como sedução, é proposto um modelo alternativo de relação que figura a diferença na metáfora da conversação ou diálogo. Bakhtin lembra-nos que o diálogo ocorre num "campo de linguagens em choque", pois os discursos estão sempre situados ao longo de relações de poder nas suas relações de endereçamento. Enquanto a prática tradutória de Brossard, privilegiando afinidades sonoras, tende ao erótico, sua teoria da tradução, como demonstrarei adiante, dá lugar de destaque para a conversação e o conflito. É estabelecida, então, uma conexão entre sua obra e as práticas tradutórias feministas no Canadá. A "version converse" anuncia um título em Tessera que introduz sete versões diferentes de "Espaces vers", uma em francês, por Lola Lemire Tostevin, e seis variantes em inglês, pelos editores de Tessera (incluindo Daphne Marlatt). O serialismo (ou diferentes perspectivas de um tópico) é anunciado no subtítulo como estratégia pela palavra "seqüência" ("uma sequiência de traduções"). A dispersão reina desde os primeiros versos onde "vers" é variadamente traduzido como "green", "lines", "where", "versions"("verde", "versos", “onde", "vers-ões"). Não há sentido singular no poema: as palavras podem ser rearticuladas de várias maneiras e de várias perspectivas, de acordo com a postura ou a estratégia do tradutor. As alterações entre um texto e outro engendram o deslizamento ou a contaminação da(s) língua(s), que a introdução de Tostevin saúda como "possibilidade de uma revelação de diferenças" que irá deslocar uma "ilusão de autenticidade e pureza" (14). "A contaminação significa que diferenças foram aproximadas de modo a fazer contato" (13). O equívoco é inscrito dentro do texto, mostrando que a pureza da linguagem é uma ficção (im)possível. Tostevin convida "Ad infinitum" (14), em vez de terminar colocando em primeiro plano o trabalho entre as línguas como o produto de leitura que cria significações através do desejo de plenitude ou completude de sentido. $O$ desejo de traduzir desencadeia traduções parciais, coloca em movimento uma série de aproximações, modulações, ou acentos. $\mathrm{O}$ tradutor pode resistir à política do texto-fonte e alterá-la para expor seus lances políticos - tradução como o-posição. Ou o tradutor pode estender as implicações do texto através de con-versações, como os tradutores de Tostevin propõem, ou como a Maude Laures fictícia faz - tradução como com-posição. A leitora/tradutora traz a outra mulher para existir em si como escrita. A violência da letra é exposta quando o trabalho de uma mulher como o outro silencioso que apóia uma economia de verdade como castração ou aufheben é posto a nu e transformado no trabalho de leitores que lêem de um ângulo diferente. As letras são atravessadas por uma outridade no que é uma escrita em palimpsesto através do outro. A repetição da tradução reestrutura e então lança à frente imagens que estão em processo de transformação. Isso participa da existência

REVISTA DE ESTUDOS DE IITERATURA

Belo Horizonte, v. 5 , p. $155-782$, out. 97 
de uma economia de pensar uma coisa através de outra, não uma coisa como separada e distinta de outra, mas a conceitualização do espaço entre elas como uma relação diferencial ou um movimento ainda não completo. A tradução distancia-se do sonho (impossível) da identidade ou equivalência total para reconhecer a criatividade poética do tradutor e as possibilidades de traduções enfáticas ou propagandísticas.

Essa figura da conversação, com seu conceito dinâmico de significado, coloca em destaque a tradução como performativa, que trabalha (n)o entrelugar, negociando a vez de mover um sistema de signos para dentro de outro. $O$ movimento, uma ação que produz efeitos, é também um tropo, um deslocamento ou escolha de sentido em um evento discursivo. A tradução como interpretante ou imagem de uma linguagem desencadeia uma seleção entre significantes que produz efeitos específicos. Um ato de perlocução, a tradução é uma promissória ou contrato de compromisso para produzir sentido equivalente. A promissória oferece sedutoramente a promessa de "verdade", ao mesmo tempo que brinca com a auto-referencialidade dos performativos para efetuar os atos discursivos que eles colocam em cena (Felman 39-40). Pois o jogo da sedução consiste em produzir uma ilusão referencial em uma afirmação auto-referencial. Ao enfatizar a auto-referencialidade de verbos performativos, essa sedução explora simultaneamente a auto-referencialidade do desejo do interlocutor para produzir uma ilusão especular, empregando um débito reflexivo onde dentro/fora, eu/ outro implicam-se. Em relação à tradução, o que uma teoria dos performativos introduz é uma mudança de uma teoria constatativa do discurso, que estrutura exigências de verdade em termos de verdade ou traição de semelhança, para uma exigência performativa que considera o significado em termos de satisfação ou falta de satisfação das condições de adequação do endereçamento - a verdade por adequação. Em resumo, a questão da (in)fidelidade. A dimensão do prazer desloca o critério de verdade em relação à proposição lingüística. $O$ que o performativo encena é o risco da perda, a lacuna entre intenção e ato, no que diz respeito à situação de enunciação e seus gêneros de discurso. A fidelidade às palavras de alguém ou à forma contextualmente apropriada incita ao fechamento, pois a promessa foi cumprida. A infidelidade - palavras repetidas em contexto diferente e inapropriado - , no entanto, põe em jogo a condição que gera a promessa e, simultaneamente, o princípio da reiteração, condição de começar outra e outra vez. A promessa é, então, a figura da falta, uma promessa de metáfora ou transposição na tradução. Na repetição reside a condição de fidelidade, a repetição que prolonga a falta. Como tal, a promessa é encenada como anáfora (Felman 52). A elocução funciona como um processo, na instância de uma enunciação, que expõe o lugar e a energia do sujeito e considera a linguagem como um imenso halo de implicações, efeitos, voltas e reviravoltas. Compromete-se teatralmente com uma união e uma dispersão de energia no realinhamento de limites, uma circulação de desejo na qual subjetividades são constituídas e reconstituídas em relação a uma sucessão de objetos ou imagens transicionais (Feral). É dentro dessa teoria da satisfação sempre adiada, de uma cadeia ou transmissão infinda de significantes em desejo de significado, que Kristeva escreve: “o teste do amor é um teste de linguagem: de sua univocalidade... Impossível, inadequada, imediatamente alusiva quando se a quer direta, a linguagem do amor é um vôo de metáforas: é literatura... No êxtase amoroso, os limites da identidade são perdidos ao mesmo tempo em que êxtase amoroso, os limites da identidade são perdidos ao mesmo tempo em que se nubla a precisão de referência e sentido no discurso d' amor é "ce qui se joue entre l'un et l'autre" (12):
completa em si, mas sempre plural e fragmentada.

O amor para uma mulher, escreve Nicole Brossard, é o mesmo que releitura ("délire") ou tradução, um vôo de metáforas ou, mais precisamente, de metonímias, de uma coisa tocando outra e despertando novas possibilidades, novas ficções. A leitura ou a tradução, para Brossard, funcionam como a análise para Kristeva, produzindo a intervenção de um terceiro, de um "sujeito analisante", dentro da relação dual entre o eu e o outro - o outro com quem é feito o jogo intersubjetivo da neurose ou a ruína da identidade psicótica no apagamento de limites. A intervenção de um analista no lugar do Outro, absorvendo a negatividade da fusão, desvia e abre um sistema para o potencial da reciprocidade da transferência e da contratransferência, exercendo um duplo movimento de deslocamento e de estabilização/desestabilização. Isso confere dinamismo ao sistema e apresenta a possibilidade de renovação (Kristeva 2327) A partir do "Le Desert Mauve" de Laure Angestelle, são geradas duas outras ficções, cada qual com diferente ângulo em relação a personagens, cenário e acontecimentos. O livro Le Desert Mauve é composto de três ficções, narrando o espaço dos seus encontros, negociações e transformações de sentido. A terceira, "Mauve, l'horizon", é uma repetição da primeira, "Le Desert Mauve", ou "lipsynching" (DM 39). Através da dêixis, autora e tradutora tomam a posição intercambiável do "eu" e "tu", encenando uma troca recíproca. Assim, em "Autoportrait de Maude Laures", o auto-retrato da tradutora alterna-se entre a segunda e a terceira pessoa no processo de duplicação no qual o sujeito da enunciação e o sujeito da elocução são, além disso, fendidos pelo sujeito da fala ou, precisamente, da escrita. $O$ eu é visto como personagem na ficção do outro. Maude alterna entre a posição de autora ("eu"), destinatária ("tu") e 
personagem ("ela") em suas elocuções. Não há pressa para alcançar um "nós" sintetizante, mas um prolongamento dos (inter)câmbios entre os dois "eus". Brossard compara esse processo de auto-investigação a um jogo de tênis, onde a bola que vai e volta figura a reversibilidade das posições: "Tu observes ton adversaire. Tu voudrais anticiper chacun de ses mouvements" (DM 120). "Tu" procura entender a razão embutida nos capítulos sobre o "homme long", a figura masculina que deflagrou e fotografou uma explosão no deserto. Ele está no bar ao lado de Angela quando ela morre, sendo aparentemente responsável por sua morte. ${ }^{16}$ Essa especulação leva à dissolução do "tu", um movimento para outra posição. "Tu perdes ton équilibre" (121). Com a perda do equilíbrio e a conseqüente mudança de ritmo, o "eu" assume seu papel e pergunta a Maude Laures como um livro de segunda mão pode mudar sua vida ("Dis-moi comment ce livre 'innocent' est venu dans ta vie interrompre ta routine de fille studieuse, a dédoublé en toi le portrait car, tu le sais fort bien, Maude Laures enseignait depuis trois ans dans un collège de filles", 121). Com a referência à duplicação, a frase desliza para a terceira pessoa "ela", a fim de fornecer um retrato "objetivo" da "vida" ou anedota da tradutora que é resumida numa afirmação irônica de seus objetivos: "éviter toute confusion entre les hommes et la réalité, isoler les paradoxes, donner suite à ses pensées les plus impudents" (122). Os dois primeiros objetivos foram violados pelo jogo de duplos que faz proliferar paradoxos na relação entre ficção e realidade, entre personagem e autora. Estes ramificam-se, e Maude, preparando-se para "mudar de personagem" ("mudar de caráter"), "imagine encore des scènes" (122-23).

A "cena" introduz a metáfora da representação ou a linguagem como espetáculo e a encenação da subjetividade para uma audiência específica. Ela também entra em ressonância com a teoria freudiana e suas implicações da cena primitiva, significativa para a constituição do sujeito dentro do contrato edípico e do "romance familiar". Uma dessas cenas coloca a personagem Mélanie em uma discussão acirrada com sua mãe, Kathy, devido ao exclusivo envolvimento desta com Lorna, deslocando, assim, o "romance" convencional para o campo de uma maternidade inadequada(128). "Fundadoras" na narrativa de Brossard, essas cenas re-presentam uma economia não-edípica de relações, que apresenta uma mulher olhando para si própria através dos olhos de outra mulher. A última "cena" que a tradutora imagina antes de contemplar o deserto

16. 0 reloto do explossio e dos fotos está nos partes numerodos dos copítulos, nas quais a voz mosculino é confinada camo "fiç̧ōo". Bem no meio do livro, entre os póginas 102 e 118 , está impressa uma toto de um fichário rodeado por fotos esmaecidos que incluem rostos de homens. Uma é de um homem olhando-se on espetho, porém o espelho nóo reflete sev rosto. Na fotografía do fichario esta escritio: "L homme long" e essas imogens scio otereccidas como seu "portroir". A dobro estáa entre o "p constitui, a meu ver, a cena central do livro: reúne tradutora e autora em um café, envolvidas em um diálogo sobre o texto que elas estão escrevendo conjuntamente. $O$ que está em jogo aqui é a linha tênue entre ficção e realidade, linha que, se ultrapassada, resulta em morte - uma meditação sobre o "poder" da escrita em produzir mudança. Ainda assim, o diálogo continua: "La réalité est ce que nous inventons" (142). A imaginação ou a semiose produz ficções do "real" com efeitos de "real". Contudo, nesse jogo, a "autora" tem a vantagem da precedência. Maude Laures escreve a cena: “Jen'ai aucun droit. Vous m'êtes antérieure" (140). Essa prioridade é marcada na linguagem da cena que, conforme somos informados, é a da autora (140). Escrevendo a ficção sempre sozinha, a autora está, entretanto, dispersa nas muitas pessoas e objetos do texto. A descrição da cena no café enfatiza o paralelo entre a autora e a tradutora. Ambas fumam, ambas se preocupam com a morte como o limite da ficção. Barthes realmente está escondido nas entrelinhas. "Toutes deux aimant composer avec le silence mais chacune ici cherche à comprendre comment la mort transite entre la fiction et la réalitê" (140). A ênfase no silêncio, no irredutível, como ponto de dissolução dos limites do "eu" é uma preocupação ética com a condição do saber, com a maneira como o mundo é construído pelo sujeito escritor.

Nesse encontro cara a cara da autora e da tradutora, imaginado pela tradutora (Maude), é a morte da personagem, Angela Parkins, que é de interesse primordial para a tradutora, que quer entender as razões de sua morte, tanto porque é a atração que ela sente por essa personagem que a leva a traduzir o livro e se alongar nele ("à t'allonger"; 122), quanto porque, sem um entendimento desse silêncio ou lacuna, ela não poderia traduzir a narrativa. Pois a relação da autora (Laure) com a personagem permanece opaca, e as contingências infletidas em sua retórica, desconhecidas. Assim que essa questão é levantada pela tradutora, em sua conversa com a autora, ela é reestruturada em um outro encaixe como uma questão da personagem para o autor, de "Angela" para "eu", que pode ser Laure, Maude, ou ambas. A tradutora se torna novamente a ficção da autora em um movimento recíproco. Estruturado em tipografia diferente (itálicos), esse diálogo embutido da personagem/tradutora e da autora dá a explicação da autora a Angela sobre sua morte súbita e assim responde obliquamente à pergunta de Maude. Ao responder à sua atração por Mélanie, a personagem Angela tomou atitudes precipitadas e esqueceu-se de olhar à sua própria volta. Ela, então, cruzou o limiar entre ficção e realidade, limiar marcado por um homem - uma alteração na perspectiva e na modalidade da contemplação, o limite da linguagem ou da morte. Isso está figurado no movimento para dentro das fotografias, com seu maior efeito de real, na parte 
"L'homme long". Se ele a tivesse apenas barrado, diz a autora (Laure), Angela teria reagido e arruinado sua vida. Então, para salvá-la disto, a autora a matou. Angela reivindica seus direitos de ser responsável por suas próprias ações, enquanto que, para a autora, essa é a força da realidade intervindo, força da perspectiva da autora, que controla a ficção.

Em um momento posterior, a tradutora assume uma posição de queixa, reclamando por seu direito, como leitora, de criticar o que existe no texto da autora. Esse protesto é também silenciado pela autora, que faz com que Maude se lembre dos limites da tradução, da inevitável incompreensão da leitura em uma língua estrangeira, da (re)escrita contra a corrente. Assim como a autora tem direito de vida e morte sobre a personagem, ela também tem uma relação desigual com a tradutora. A autora (LA) insiste: "Comment pouvez-vous me comprendre si vous me lisez dans une langue et transposez simultanément dans une autre ce qui ne peut adéquatement trouver place en elle?"(143). "Adequadamente" é a palavra crucial que enfatiza os limites da equivalência ou correspondência (mimesis) entre línguas em uma teoria de adequação ou poiesis. Paisagens são imagens que excedem da linguagem e servem como cadeias de produção de desejo - replica a tradutora $(\mathrm{ML})$, recorrendo à maior transparência dos signos visuais. Mesmo essas paisagens são incomensuráveis - responde a autora -, em vista das diferentes condições de conhecê-las, de diferentes perspectivas e, logo, dos conhecimentos culturais que as in/formam: “Comment croire un instant que les paysages qui sont en vous n'effaceront pas les miens?" (143). A opacidade das imagens embaçadas e sem rosto do dossiê de fotos do "L'homme long" fala do trabalho de interpretação necessário para ler até mesmo os signos visuais que não são de modo algum "transparentes". Entretanto, um paralelo pode ser traçado entre escrita e tradução, entre repetição e duplicação do processo (não entre conteúdos), que faz conexões através desse silêncio, por meio de condições distribuídas de elocução. A "autora" descreve como chegou a escrever o seu texto depois de ter lido uma carta de amor de uma mulher para outra, dobrada dentro de um texto geológico. Na fícção resultante, ela imagina o rosto da outra mulher, que ela queria ter conhecido. Assim também, como esse trecho demonstra, a tradutora apaixona-se por uma personagem em um livro e quer trazê-le à vida em sua escrita. Nesse sentido, a "autora" concorda: paisagens nos deslocam do familiar e nos colocam na cena da escrita como busca para produzir um efeito de estranhamento. Mesmo havendo, aqui, uma repetição do processo, escrita e tradução continuam sendo duas atividades distintas, não apenas em termos de precedência temporal, mas também no que diz respeito à proximidade dos desejos das personagens, como a linguagem dessa conversa demonstra. Autora e personagem travam diálogo no modo de tratamento familiar je/tu, mas autora e tradutora conversam no modo formal e assimétrico do je/vous, separadas por relações de poder em torno de uma certa "évidence" de palavras (143), a realidade ou limite da representação com o qual, como a morte, elas confabulam. Uma das mudanças significativas na versão de Maude Laures do encontro de Mélanie e Angela confirma isso. Enquanto a versão de Laure enfatiza a sensualidade do corpo de Angela e o desinteresse do rosto, a versão de Maude destaca o toque das faces que conecta Angela e Mélanie/eu tão proximamente que "exceto pela eternidade, não há espaço entre nós. Somos o deserto e a evidência" (219). Na reescrita de Maude, que insiste em "quelques mots concis" e na força da memória (220), é concedido poder total de criação à festa da linguagem. Angela anuncia sua existência e então ilumina o horizonte para Mélanie/Maude no momento em que dançam juntas. Entretanto, embora as imagens da violência sejam atenuadas, Angela ainda termina no chão, "seu corpo para sempre inflexível", e o "hom'oblong" "completamente distante da cena" (220). O poder de criar da tradutora é novamente posto em cheque pela ação do enredo, que restringe suas transformações ao colorido da paisagem para transmitir uma representação mais positiva do amor lésbico. "La réalité concise" (50) da perspectiva de Laure Angestelle intervém para repetir a morte de Angela e deixar que a tradutora confronte a perda.

Amor, tradução e os limites do "eu" que eles impõem incitam paradoxalmente à escrita além dessa morte, à representação que continua a delimitar e a viver. A ficção de Brossard sobre a tradução enfatiza os limites da identidade, em sua explosão da incomensurabilidade das línguas e seu foco na tradução cultural, na ausência da tradução linguiística. Na sua preocupação com o espaçamento da retórica, com as relações dentro das quais a linguagem é vivida e que excedem a língua e todavia a conformam através de ritmo e posicionamento, Le Desert Mauve narra o processo de construção de um modelo para a outra língua que detém a promessa de uma modalidade de tradução que substituirá a violação por criação e a morte por amor e vida. Não há inspiração divina nessa tradução de culturas, não há maravilhas, mas trabalho político de intercâmbio e transformação. A diferença que " $L$ " faz é transformar anjos [angels] em ângulos [angles], oferecendo uma apreensão material do "real". Escrever na pós-vida coloca a linguagem à prova, mas não oferece nenhum momento de revelação, levando-nos de volta para as contingências das línguas na praxis.

Tradução: Marília Scaff
REVISTA DE ESTUDOS DE LITERATURA

Belo Horizonte, v. 5 , p. 155 - 182, out. 97

\section{[1]国}




\section{ABSTRACT:}

This paper analyzes the translation theory advanced in Canada by Nicole Brossard in Le désert mauve (Mauve Desert) which attends to the affective and embodied dimensions of translation. Proposing a feminist theory of cultural contact as a loving relation, this fiction probes the excitements and dangers of embracing the other. In the process, it rewrites Benjamin's theory of the translating angel with its notion of a transcendent afterlife in the intentio of a "pure language", to advance instead a theory of translating angles, translation as transformation from a shift in perspective that involves a spatial and cultural change in location with a consquent difference in meaning. KEY-WORDS:

Feminist Theory of Translation, Rewriting Benjamin, Translating Angles 